\title{
China's catching up in aerospace
}

\author{
Jorge Niosi*
}

Department of Management and Technology,

Canada Research Chair on the Management of Technology,

University of Quebec at Montreal,

P.O. Box 8888 Station Centre-Ville,

Montreal, QC, H3C3P8, Canada

Fax: 1-514-987-3343

E-mail: niosi.jorge@uqam.ca

*Corresponding author

\section{Jing Yuan Zhao}

Canada Research Chair on the Management of Technology,

University of Quebec at Montreal,

P.O. Box 8888 Station Centre-Ville,

Montreal, QC, H3C3P8, Canada

E-mail: JingYZh@gmail.com

\begin{abstract}
Since the foundation of the People's Republic in 1949, China (PRC) has made strong efforts to build an independent aircraft industry, both civilian and military. During the first decade of its existence, the PRC received technology from the Soviet Union, while it started to build its domestic public institutions for research and teaching. After the Sino-Russian split in 1966, the flow of Soviet technology ebbed. Since 1972, the PRC started progressively to tap Western sources of technology, and is now close to launch its own commercial aircraft industry with a view to global markets. The paper analyses the strategies of the Chinese government for domestic institution building and international technology transfer, and how Western companies and governments helped China to nurture its future competitors.
\end{abstract}

Keywords: international aircraft industry; China's catching up; government support.

Reference to this paper should be made as follows: Niosi, J. and Zhao, J.Y. (2013) 'China's catching up in aerospace', Int. J. Technology and Globalisation, Vol. 7, Nos. 1/2, pp.80-91.

Biographical notes: Jorge Niosi is Professor at the Department of Management and Technology, Université du Québec à Montréal since 1970 and Canada Research Chair on the Management of Technology since 2001. He is the author, co-author, Editor or co-Editor of 15 books, the latest being Building National and Regional Innovation Systems, Cheltenham, Elgar, as well as some 60 articles in refereed journals including the Cambridge Journal of Economics, Industrial and Corporate Change, Journal of Business Research, Journal of Development Studies, Journal of Technology Transfer, Management International Review, Research Policy, R\&D Management, Small Business Economics, Technovation and World Development. 
Jing Yuan Zhao was a Post-doctoral Researcher and Senior Lecturer at the Postdoctoral Centre and School of Management, Harbin Institute of Technologies (China). Her PhD is in Management Science and Engineering in Chinese Academy of Sciences (CAS) and University Science and Technologies of China (USTC). Her expertise is on regional innovation management, high-tech industry cluster, knowledge management, technologies diffusion, and organisation learning. She serves as a Guest Editor for several international journals and is an Invited Reviewer for China' state-run newspaper West Times to provide comments on the economy.

\section{Introduction: the Soviet era}

Before 1949, Chinese aircraft was entirely imported. There were no local capabilities for design or manufacturing and only a few repair shops had been established. In 1951, the government published a 'Resolution on Building an Aviation Industry', and a Bureau of the Aviation Industry (BAI) was created. The first five-year plan (1953-1958) announced the construction of several aircraft factories to produce military aircraft with Soviet assistance.

While the plan seemed audacious, in a few years China was producing and exporting military aircraft to allied countries. The first factories were located in Chengdu, Harbin, Nanchang and Shenyang. Since 1954, China started producing a military trainer at Nanchang, then a subsonic jet fighter in 1955 (the CJ5 at Shenyang, a Chinese version of the Russian MIG-17). Over 1800 copies of this jet were built between 1956 and 1992. A first supersonic jetfighter, the J-6, a Chinese version of the Soviet MIG-19, was launched in 1958 and produced in 3000 copies between 1958 and 1981, for both local and international armed forces. The production of transportation and utility aircraft started at Nanchang in 1957 It was the Y-5 aircraft, a version of the Antonov An-2, a biplane turboprop; over 700 copies of it were produced at Nanchang, many of which are still used. Different versions of this aircraft were later produced in other Chinese plants. In 1959 the Harbin plant started producing the Z5 helicopter, a Chinese version of the Soviet Mi-4. When production stopped in 1980 some 545 units had been built, mainly for civilian uses. Engines started to be produced at a new Zhuzhou plant in 1959.

Two factors led to the end of this period of intense Chinese aircraft development. One was the Great Leap Forward, launched in 1958, which disorganised the existing plants with frequent movements of facilities and personnel. The second was the Sino-Soviet disputes starting in early 1960s and culminating in the Cultural Revolution (1966-1976). The Chinese aircraft industry was thus left alone and did not register major advancements for over a decade. The Z-6 helicopter, for instance, entirely designed in China, was produced in only 15 copies between 1966 and 1977, due to technical problems, and was abandoned. The Chinese authorities decided that many technologies were needed if domestic aircraft was to be able to compete with foreign-made ones. 


\section{Leaning towards the west}

In 1972, the historical visit of President Nixon to China opened a new era for US-China relationships. A few years later, China started producing parts of, and importing the MD-82/83 airliner. Since 1987, a Chinese version of the MD-82 was entirely assembled under license at a factory in Shanghai Aircraft Manufacturing Company, in cooperation with the Chengdu, Shenyang and Xian manufacturing plants.China provided a few components to the 35 planes produced in China under MD Corp. guidance and assistance.

China aircraft ambition was also evident in helicopter design and manufacturing. In the early 1970s, China had imported 13 French helicopters SA-321Ja and started reverseengineering them at the Changhe plant. In 1985, the first Chinese version, named Z-8 flew but, once again due to technical problems, only 20 copies of it were produced. Since then, a large number of technology transfers and subcontracting involved basically all Western producers of civil aircraft and Chinese corporations.

\subsection{Institution building for absorbing foreign technology}

At the end of the 1950s, the BAI was transformed into a full-fledged department, the Third Ministry of Machine Building. In 1982, it became the Ministry of the Aviation Industry and later the Ministry of the Aviation and Aerospace Industry. In 1993, the Ministry spun-off a very large government company, China Aviation Industry Corporation (AVIC), with close to half a million employees and numerous factories and institutes across the country. In 1999, AVIC was split into two different companies, AVIC I (focusing on large aircraft, bombers and fighters), and AVIC II(aimed at producing light aircraft and helicopters). Both corporations received different but confused mandates and launched redundant projects; in 2008 they were merged to become again a single corporate entity, AVIC.

AVIC operates in such segments as air transportation aircraft, civil and military, helicopters, engines, avionics and general aviation, but also in automobiles. AVIC many subsidiaries include Changhe Aircraft Industries, Chengdu Aircraft Industry, China Nanchang Aircraft Manufacturing Corp., China National Aero-Technology Import and Export Corp., Ghizhou Aircraft Industry Corp., Harbin Manufacturing Corp., Hongdu Aviation Industry Group, Shanghai Aviation Industrial Co., Shanxi Aircraft Co., Shenyang Aircraft Corp., and Xian Aircraft Industrial Corp (DeFilippo, 1997; Dougan, 2002; Gordon and Komissarov, 2008). Many of these subsidiaries, as we shall see, have signed independently technology transfer and subcontracting agreements with companies based in the USA, Canada, France, Italy, and Germany. They have also, by themselves or with other sister companies, participated in the design and development of several domestic aircraft, as well as manufacturing under license of existing aircraft.

\subsubsection{Universities}

Institutional change did not stop at the corporate level. Several universities in China now offer advanced degrees in aerospace and aircraft design, engineering and manufacturing. They are all eager to learn from foreign countries higher education organisations. They include the Beijing University of Aeronautics and Astronautics (BUAA), the Nanjing Aeronautics and Astronautics University (NUAA) in Nanjing, the Harbin Institute of 
Technology, Tsinghua University (Beijing), and the Northwestern Polytechnic University (NWPU) in Xian.

- BUAA is one of the oldest and largest higher education institutions focused on aerospace; founded in 1952, it now enrols over 26,000 students, 3300 faculty and staff, and boasts 88 laboratories. BUAA has signed 152 cooperation agreements with universities and research institutes in 40 countries including Canada, the UK, France, Germany, Russia and the USA. Every year over 1000 foreign experts are invited to the university to give lectures and conduct research.

- Founded in 1952, NUAA is another university entirely devoted to aerospace. It enrols some 13,100 students, and 1400 faculty members. With 50 research institutes, NUAA has signed cooperative agreements with over 20 universities in the US, the UK, France, Germany and Russia. NUAA has evolved from a teaching technical university into a complete research institution.

- Established originally in 1938 as State Northwest Institute of Engineering, in Hanzhong, central China, the institution was moved to Xian in 1957, and was renamed Northwestern Polytechnical University (NPU). NPU enrols over 28,000 students and more than 3,500 faculties. Among its 14 schools, half deal with aerospace, astronautics, automation, advanced materials, mechanical engineering, and electronics. It has signed partnerships with over 100 overseas universities, public research institutes and private enterprises in Australia, Belgium, Canada, Denmark, Finland, France, Germany, the Netherlands, Russia, Spain, the UK and the US. Its Aircraft Department was founded in 1952, and its National Laboratory of Aerodynamics Design and Research owns the largest low-speed wind tunnel in Asia, as well as several other wind tunnels. The School of Aeronautics alone has some 1700 students, and has produced over 10,000 graduates.

- Harbin Institute of Technology (HIT) was founded in 1920 and enrols today some 42,000 students, and 2,900 full-time teachers and professors. HIT has signed cooperation agreements with 126 institutions in 26 countries, including the US, the UK, France, Germany, Japan, and Russia. In 2007, it had over US\$ 150 million in research funds. HIT includes a School of Astronautics representing alone some 20\% of the Institute's students.

- Tsinghua University, one of the top higher education institutions in the country, includes China's School of Aerospace. The School was founded in 2004, on the basis of several pre-existing departments.

\subsubsection{Public laboratories}

The public institutional infrastructure includes over 30 public laboratories. The first public aerospace research institutes were founded in the 1950s. While in the West they are independent and under the aegis of one government department, such as Industry or Defence, in China these are under these labs are subsidiaries of AVIC (Table 1). These laboratories are very large and technically improving. 
Table 1 China's Main Aircraft Research Institutes

\begin{tabular}{|c|c|c|c|}
\hline Name (year established) & Location & $R \& D$ personnel & \\
\hline Beijing Institute of Aeronautical Materials & Beijing & 1,400 & 1 \\
\hline China Aircraft Strength Research Institute & Xian & 1,100 & 2 \\
\hline Gas Turbine Research Institute & $\begin{array}{l}\text { Jiangyou, } \\
\text { Sichuan }\end{array}$ & 900 & 3 \\
\hline $\begin{array}{l}\text { Beijing Aeronautical Manufacturing Technology } \\
\text { Research Institute }\end{array}$ & Beijing & 800 & 4 \\
\hline Shenyang Aero-Dynamics Research Institute & Harbin & 160 & 5 \\
\hline Harbin Aero-Dynamics Research Institute & Harbin & 488 & 6 \\
\hline China Flight Test Establishment & Xian & 2,000 & 7 \\
\hline $\begin{array}{l}\text { China Aeronautics Computing Technique Research } \\
\text { Institute }\end{array}$ & Xian & 800 & 8 \\
\hline $\begin{array}{l}\text { Shanghai Aeronautical Measurement-Controlling } \\
\text { Research Institute }\end{array}$ & Shanghai & 300 & 9 \\
\hline $\begin{array}{l}\text { Beijing Chang Cheng Aeronautical Measurement and } \\
\text { Control Technology Research Institute }\end{array}$ & Beijing & 160 & 10 \\
\hline $\begin{array}{l}\text { Jinan Research Institute for Special Aeronautical } \\
\text { Composites }\end{array}$ & Jinan, Shandong & 200 & 11 \\
\hline $\begin{array}{l}\text { China Aviation Precision Machinery Research } \\
\text { Institute }\end{array}$ & Beijing & 150 & 12 \\
\hline $\begin{array}{l}\text { Beijing Changcheng Institute of Metrology and } \\
\text { Measurement }\end{array}$ & Beijing & 520 & 13 \\
\hline China Air to Air Missile Research Institute & Luoyang, Henan & 2,500 & 14 \\
\hline Shengyang Aircraft Research Institute & Liaoning & 1,100 & 15 \\
\hline Xi'an Aircraft Design and Research Institute & Xian & 1,600 & 16 \\
\hline Shenyang Aero-engine Research Institute & Liaoning & 900 & 17 \\
\hline China Leihua Electric Technology Research Institute & $\begin{array}{l}\text { Neijiang, } \\
\text { Sichuan }\end{array}$ & ND & 18 \\
\hline China Research Institute of Aero-Accessories & Xiangfan, Hubei & 900 & 19 \\
\hline China Aviation Life-Support Research Institute & Xiangfan, Hubei & 820 & 20 \\
\hline Chengdu Aircraft Design Institute & $\begin{array}{l}\text { Chengdu, } \\
\text { Sichuan }\end{array}$ & 1,400 & 21 \\
\hline Luoyang Opto-Electrotechnology Development Centre & Luoyang, Henan & 500 & 22 \\
\hline Wuxi Aero-engine Research Institute & Wuxi, Jiangsu & 250 & 23 \\
\hline $\begin{array}{l}\text { Chinese Aeronautical Radio Electronics Research } \\
\text { Institute }\end{array}$ & Shanghai & 544 & 24 \\
\hline Xi'an Flight Automatic Control Research Institute & Xian, Shaanxi & ND & 25 \\
\hline Shanghai Aircraft Research Institute (1973) & Shanghai & ND & 26 \\
\hline China Institute of Aeronautical Systems Engineering & Beijing & 110 & 28 \\
\hline Chinese Helicopter Research Institute & Jiangxi & 1,400 & 29 \\
\hline
\end{tabular}


- One of the first, and today China's largest one, is the Beijing International Aeronautical Materials Corporation (BIAM). Founded in 1956, its mission is to conduct advanced R\&D in aerospace materials such as titanium, aluminium alloys and super-alloys, and composite materials. BIAM has a total staff of some 2,700, including 1,400 research personnel.

- Another major institute is China Gas Turbine Research Establishment (CGTE) in Chengdu. CGTE was founded in 1965, enrols some 900 R\&D staff, and conducts $\mathrm{R} \& \mathrm{D}$ in the aero engine industry.

- A third one deserving special mention is the Chengdu Aircraft Design Institute (CADI), a subsidiary of the Chengdu Aircraft Industry Corporation. Founded in 1970, under its parent company (itself established in 1958), CADI has 1,800 employees of which, 1300 are technical people covering 80 disciplines.

In sum, since 1949, China has proceeded to create a large number of academic and research institutions, and transformed them into centres of learning and in-ward technology transfer. From the Soviet era (1949-1966) to the Western era (since 1972), China has enlarged the number of its suppliers of knowledge in the area of aircraft and aerospace, and is fast becoming a producer of knowledge itself.

Table 2 Technology transfer through Western outsourcing programs (selection)

\begin{tabular}{lccc}
\hline Assembly/component & Assembler/client and aircraft & Chinese factory location & Year \\
\hline Final assembly & MD-80 & Chengdu & 1988 \\
$\begin{array}{l}\text { Components for } \\
\text { commercial engines }\end{array}$ & Pratt \& Whitney & Chengdu & 1996 \\
Vertical fin & Boeing 737 & Xian & 1996 \\
$\begin{array}{l}\text { Environmental control and } \\
\text { other systems }\end{array}$ & Honeywell & Nanjing & 1997 \\
Final assembly ERJ-145 & EMBRAER & & \\
Vertical fin composite & Boeing 787 & Harbin & $2003 / 11$ \\
rudder & & Chengdu & 2005 \\
Wing-to-body fairing panels & Boeing 787 & & \\
Vertical fin composite edge & Boeing 787 & Harbin & 2005 \\
assembly & & Shenyang & 2005 \\
Final assembly plant & Airbus A 320 & Tianjin & 2008 \\
Wing assembly & Airbus A 320 & Xian & 2009 \\
Landing gear, nacelles & Goodrich for COMAC 919 & Xian & 2009 \\
Fly-by-wire systems & Honeywell /COMAC 919 & Xian & 2010 \\
$\begin{array}{l}\text { Communications and } \\
\text { navigation equipment }\end{array}$ & Rockwell Collins /COMAC & Chengdu & 2010 \\
Fuselage barrels & 919 & & \\
Doors and tail & Bombardier C-Series & Shenyang & 2010 \\
Composite parts & Bombardier Q 400 turboprop & Shenyang & 2011 \\
Legacy Business jet & Airbus A 350 & Harbin & 2011 \\
Rear doors & EMBRAER & Harbin & 2012 \\
Exit doors & Airbus A 320 & Chengdu & ND \\
\hline & Airbus A 320 & Shenyang & ND \\
\hline
\end{tabular}




\section{Building up capabilities through subcontracting, and licensing}

Since 1972, China has multiplied and intensified its relations with Western aerospace companies (Gordon and Komissarov, 2008; Nolan and Zhang, 2002). That year, China ordered ten Boeing 707. Starting in 1970, China had designed and built at the Shanghai factory a few copies of the Y-10, a domestic model similar to the B707; the program was abandoned in 1983 for cost and technical reasons (Chen, 2009). Since the 1970s, Boeing became the main provider of large commercial aircraft for China's thriving airlines. At the same time, China became a major supplier of parts and components for virtually all the subsequent Boeing models as illustrated in Table 2. Also, in 1992 MD (which became a Boeing subsidiary in 1997) had signed a contract to produce 40 MD 90s in Shanghai. The contract was amended in 1998 to reduce to two the number of MDs to be produced in China. Today, some ten different AVIC subsidiaries participate in supplier chains for Boeing; these include not only Shanghai Aviation Manufacturing, but also those plants in Beijing, Chengdu, Chongqing, Harbin, Sanyuan, Shenyang, and Xian. AVIC companies have also a major role in the production of the new Dreamliner airplane. And Boeing is also investing in joint ventures and wholly owned subsidiaries in China for the production of parts, subassemblies and services in that country.

If Boeing was first, Airbus is now the second major provider of technology for Chinese public companies (Eriksson, 2010). In 1985, Aerospatiale (now a member of the Airbus group) signed its first subcontracting agreement with Xian Aircraft to produce doors for the A300 and A310 aircraft. Subcontracting was extended further to other Airbus models in the following years. In response, China has bought an increasingly large number of large commercial planes from Airbus.

Brazil's Embraer also competes in the Chinese market through technology transfer (Goldstein, 2008). In 2003, Embraer built an assembly plant in Harbin to produce the ER-145, a smaller plane, for the domestic market. The plant is owned by Embraer (51\%) and AVIC (49\%). By mid-2010, Embraer was producing the last regional jets in that plant and was waiting for permission to build a larger jet, the E-190. This larger regional jet may compete with China's ARJ21, plane that would appear in the market by 2015, entirely designed and built by China's AVIC. In the meantime, Embraer announced the opening of a second subsidiary in China aimed at providing service to the 70 aircraft already flying in that country, and the many others ordered.

Bombardier of Canada, the world third largest producer of commercial aircraft felt that Embraer was positioning itself to reap the benefits of the Chinese market. By mid-2010 some 29 Bombardier regional jets were flying in China. In order to compete with the Brazilian manufacturer, Bombardier launched a major subcontracting operation in China. Its new CSeries aircraft, a larger and advanced regional jet, will be partially built in China. The Shenyang Aircraft Corporation will build the fuselage for the new model, which is expected to be in the market by 2013. The latest technologies in regional jets are thus also being transferred to China's AVIC.

What drives all the major companies to China is the fast rise of the Chinese market for aircraft. Both Airbus and Boeing forecast that China would need some 3,400 commercial airplanes in the next two decades, or some 100 to 150 new planes every year

Under such market conditions and strong institutional infrastructure, receiving technology from all the four major commercial aircraft producers, China's AVIC has announced that it will be in the regional jet market by 2015, with its own models, and a few years later, in the long courier civil aircraft market. In fact China's regional jet, the 
ARJ21, a two-engine aircraft is already designed and the prototype has made its maiden flight in July 2009. The ARJ21 uses tools and equipment provided to China by McDonnell Douglas for the manufacturing of the MD series. The ARJ21 has two variants, one with 90 seats and the second with 105 seats. GE engines made in the USA will power the jet. Ukraine's Antonov design bureau has collaborated in the aerodynamics of the plane, which bears resemblance to MD's DC-9 family.

China's ambitions in the aircraft industry also extend to a whole range of helicopters. In the last 20 years, AVIC has been collaborating mainly with US Sikorsky, and the European Eurocopter consortium. The main Chinese helicopter manufacturer is Changhe Aircraft Industries Group (CHAIG), located in Jingdezhen. Founded in 1969, CAIG has been a central player in Chinese projects to build helicopters. After several failed projects, in 1989 CHAIG's design subsidiary proposed a light helicopter inspired in the French AS350B, named the Z-11. The helicopter prototype had its maiden flight in 1994, and production started in 1997. It is a six-seat, 2,000 kg aircraft with both civil and military variants, and is the main locally produced civil helicopter in China.

Cooperation with Sikorsky started in the mid-1980s when China purchased 24 military S-70C Black Hawk units. Also, in 1997, CHAIG started producing tails and horizontal stabiliser for Sikorsky's S-92 helicopters and components for the S-76++. Sikorsky's cooperation with Chinese companies is not confined to AVIC. N 2001, the US aircraft company made a partnership with a private firm, Shanghai Little Eagle Science and Technology Co (SLEST) to jointly manufacture Sikorsky's light helicopters. In the end, a joint venture was formed involved, besides the US Sikorsky Corporation, CHAIG, SLEST, and two other Chinese companies. The JV is called Shanghai Sikorsky Aircraft Corporation (SSAC), and it started operations in 2004 in Pudong's industrial area. SSAC is now producing and selling two light helicopters made in China.

In the meantime, CHAIG had formed a joint venture with AgustaWestland (AW), now part of Eurocopter, to assemble and sell AW's A109E in Jingdezhen. In 2003, a teaming agreement was signed in China between Eurocopter and AVIC II for the joint production of all sorts of light, medium and heavy helicopters in China. As of 2009, Eurocopter had some $50 \%$ of the Chinese civil helicopter market, with 70 units. Sikorsky was the other major provider of this type of aircraft. Eurocopter is also planning an assembly plant in China, but no date has been announced for its construction and operation.

\section{The present situation of China's aircraft industry}

By 2011, China's aviation has a relatively complete industrial system of scientific research, testing, production, management, marketing, education with independent development capabilities and related products supporting, and is one of counties that can produce a series of aviation products in the world. China's aviation has become an important technology-intensive industry of Chinese economy. In July 8, 2009, China AVIC appeared in the US 'Fortune' Global 500 for the first time. By 2011 it was ranked 311 with the operating income of $\$ 31$ billion and the profit performance of $\$ 700$ million, and ranked 11 th in aerospace and defence sector in the world.

By 2009, there were 99 enterprises of civil aviation, including 48 enterprises from AVIC of China, 5 enterprises from Commercial Aircraft Corporation of China Ltd (COMAC), and 46 local civil aviation enterprises, of which there are 13 foreign funded 
enterprises and enterprises with funds from Hong Kong, Macao \& Taiwan, 8 private enterprises. COMAC was established as a new company in Shanghai. The output value of AVIC system is 7.259 billion yuan, while the local civil aviation system is 71.43 billion yuan in 2009 , accounting for $48.44 \%$ of total output value, and the value of two system is nearly the same.

Yet, both the scope and quantity of aircrafts independently developed by China still are relatively weak. For example, by the end of October 2010, China registered 1,636 civil aircraft in the transport category, but only 18 of them are domestic aircrafts, the proportion is less than $1.1 \%$.

COMAC is developing two major commercial airliners: the ARJ-21 and the C-919. Their characteristics and expected deadlines appear in Table 3.

Table 3 Aircraft in production or development of COMAC

\begin{tabular}{ccccccc}
\hline Aircraft & Variants & Description & Capacity & First flight & $\begin{array}{c}\text { Deliveries } \\
\text { expected }\end{array}$ & $\begin{array}{c}\text { Orders by } \\
\text { March 2011 }\end{array}$ \\
\hline ARJ 21 & $\begin{array}{c}700,900, \\
\text { F,B }\end{array}$ & $\begin{array}{c}\text { Twin-engine, single } \\
\text { aisle, short-range } \\
\text { narrow-body }\end{array}$ & $70-105$ & $\begin{array}{c}\text { November } \\
2008\end{array}$ & Fall 2011 & 237 \\
C 919 & NA & $\begin{array}{c}\text { Twin-engine, single } \\
\text { aisle, short- to } \\
\text { medium-range } \\
\text { narrow-body }\end{array}$ & $150-190$ & 2,014 & 2,016 & 100 \\
\hline
\end{tabular}

The ARJ-21 is initially targeting the internal market and will be selling $10-15 \%$ less than imported ones. It will also be avoiding $23 \%$ import tax on regional jets. The ARJ-21 will have Western engines, avionics and flight controls, together with Chinese design and production technology. COMAC intends to obtain US, European and Canadian certification to expand their markets overseas. Bombardier is cooperating on the ARJ-21 transferring technology to China for its advanced fuselage in order to gain orders for its new C-Series plane.

Airbus is also establishing a plant in China for its older A-320. The plant was inaugurated in 2009 and is now producing some four planes a month. In this Tianjin plant, Airbus expects to build 286 planes by 2016 .

The Chinese markets for both regional and wide-bodied aircraft are growing very fast. Some estimation put that China's civil aviation need to add all types of civil aircraft 3796 during 2009-2028, of which2,922 large jets, and 874 regional aircrafts, as well as and 2,700 civil helicopters(People's Daily, 24/9/2009). Also, Boeing forecasts that by 2026, China's domestic market will be larger than North American market. By 2020, China will have 186 airports, including 3 national hubs, 7 regional hubs, 24 medium-size hubs, 28 medium airports and 124 small-size ones.

In the meantime, all indicators point to strong growth: by 2009 , the number of airports with passenger throughput over 1 million person-trips were $51 ; 45$ airports had a cargo and mail throughput of 10,000 tons and over. In 2010, passenger throughputs of all nationwide airports reached 270 million, up by $15.8 \%$ over the last year; cargo and mail throughputs were 5.574 million tons, up by $25.1 \%$. The China Civil Aviation Bureau has indicated that the demands for passenger air traffic and cargo air traffic will grow at a steady rate of $8.4 \%$ and $10.5 \%$ respectively until 2025 . China's COMAC wants to capture part of this demand for its own products, even if Airbus and Boeing will continue to be the major suppliers of jumbos, and maybe Bombardier and Embraer will remain 
important suppliers of regional jets. The balance of imports and exports of aircraft products is still strongly negative (Table 4). China expects that COMAC will reduce the deficit by the end of this decade.

Table 4 National imports and exports of aerospace products (USD million, current)

\begin{tabular}{lccc}
\hline & Exports & Imports & Balance \\
\hline 1997 & 321 & 3,471 & $-3,150$ \\
1998 & 436 & 3,459 & $-3,023$ \\
1999 & 663 & 3,680 & $-3,017$ \\
2000 & 691 & 2,653 & $-1,961$ \\
2001 & 624 & 5,204 & $-4,580$ \\
2002 & 594 & 4,602 & $-4,007$ \\
2003 & 755 & 5,501 & $-4,746$ \\
2004 & 996 & 6,366 & $-5,370$ \\
2005 & 1,411 & 8,714 & 7,303 \\
2006 & 2,436 & 13,158 & $-10,722$ \\
2007 & 2,518 & 12,916 & $-10,398$ \\
2008 & 3,213 & 13,238 & $-10,025$ \\
2009 & 2,684 & 14,034 & $-11,350$ \\
\hline
\end{tabular}

Source: China National Bureau of Statistics (28 February 2011)

\subsection{Is China's aircraft production a threat to US and EU dominance of the industry?}

Two opposite points of view are arguing on this issue. Some authors contend that outsourcing, technology transfer and foreign direct investment by European and North American firms, combined with strong investment by China's government are already eroding (Pritchard and McPherson, 2007; McPherson, 2008). Foreign risk-sharing partners may become competitors in a few years, first and foremost among them would be China.

The opposite view appears in US government documents that bring figures about US aerospace trade with China. Official US figures are showing that not only the US has maintained a very large trade surplus in aerospace with China since 2005. Such surplus has also been expanding. By 2010, it reached over 5 billion US\$, against 3.5 billion in 2005 (US Dept of Commerce, 2011).

Also, UN trade statistics and US Dept of Commerce statistics put US exports of aircraft (civil and military) at around US\$78 billion a year by 2010; China's exports, while growing, are now at a US\$2-3 billion a year level. Similar figures for 2010 put France's exports at US\$56 billion, Germany at US\$40 billion, Canada at US\$14 billion and Japan at US\$6 billion.

In addition, Western sources indicate that most Chinese military aircraft (which include the vast majority of Chinese aircraft products) are obsolete by Western standards, particularly in avionics and acceleration. For instance, China has no military stealth fighter. Also, a focus on the internal market of its civilian production tends to indicate that the Chinese industry is unable to compete in world markets (Sweeney, 2008). And 
the goal of producing a $100 \%$ Chinese civil aircraft runs against the current trend of outsourcing on the basis of price, technology and reliability from where it fits better (Sweeney, 2008).

\section{Conclusions}

China's aerospace industry fully enjoys the follower's advantage, and is able to acquire both mature and cutting edge technologies at a fraction of the cost than the original developer has disbursed (Medeiros et al., 2005). Also, China is determined to build a strong civil aviation industry, and it is putting together all the necessary building blocks to succeed, where so many other countries have failed. Its winning cards include a strong government will and public investment in R\&D laboratories, research universities, airports, and public manufacturing corporations. Through trial and error, foreign assistance, hard work and strong pubic support, the institutional framework for catching up is being put in place.The winning cards also include a fast-growing market for all kinds of civil aircraft (wide body, regional and civil helicopters).

Other converging factors include that European and North American markets are mostly replacement, slow-growing ones. While COMAC's products are not yet using vintage technology, foreign producers are ready to share their most advanced materials, propulsion systems and avionics with COMAC in order to get a piece of the market. The catching up of China in aircraft may extend itself for the next to decades but the chances that it succeeds are higher than for any other emerging country. Figure 1 summarises the commercial aircraft manufacturing learning curve in China.

Figure 1 The commercial aircraft learning curve in China (1978-2000) (see online version for colours)

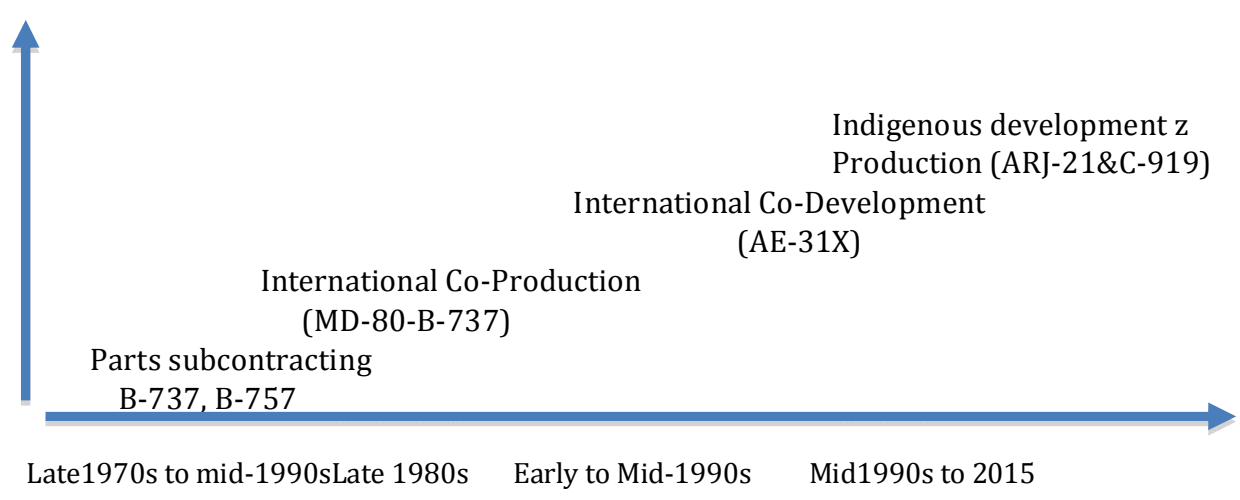

However, China is not yet threatening the commercial supremacy of Western Europe and North America in the aircraft industry (Cliff et al., 2011). China will most probably become a challenger around 2020-2025 if we compare both its learning curve with the one it posted in other industries, and the investments it is committing in this industry. China lags the West in both technology and management expertise. Debates are open about the future direction and attainments of China's aircraft industry, but all agree that its advancement in all fields of the industry have been fast and spectacular. If developing country capabilities have most often been unable to nurture an aircraft industry 
(Steenhuis and De Buijn, 2001), China, like Brazil in the recent past, may prove that the challenge can be met by large developmental states and public investments in human capital and technology development.

\section{References}

Chen, Z. (2009) 'A brief history of China's Y-10: imitation versus innovation', Technology in Society, Vol. 31, No. 4, pp.414-418.

Cliff, R., Chad, J.R. and Young, D.Y. (2011) Ready for take-off. China's advancing Aerospace Industry, RAND Corporation, Santa Monica, CA.

DeFilippo, J.S. (1997) 'World class manufacturing in Chengdu: a case study on China's first aviation joint venture', International Journal of Technology Management, Vol. 13, Nos. 5/6, pp.681-695.

Dougan, M. (2002) A Political Economy Analysis of China's Civil Aviation Industry, Routledge, New York and London.

Eriksson, S. (2010) 'China's aircraft industry: collaboration and technology transfer - the case of Airbus', International Journal of Technology Transfer and Commercialisation, Vol. 9, No. 4, pp.306-325.

Goldstein, A. (2008) 'A Latin American global player goes to Asia: Embraer in China', International Journal of Technology and Globalisation, Vol. 4, No. 1, pp.56-69.

Gordon, Y. and Komissarov, D. (2008) Chinese Aircraft, China's Aviation Industry since 1951, Hikoki Publications, Manchester.

McPherson, A. (2008) 'The emergence of a new international competitor in the commercial aircraft sector: the China syndrome', Futures, Vol. 41, No. 7, pp.482-489.

Medeiros, E.S., Cliff, R., Crane, K. and Mulvenon, J.C. (2005) A New Direction for China's Defense Industry, Rand Corporation, Santa Monica CA.

Nolan, P. and Zhang, J. (2002) 'The challenge of globalisation for large Chinese firms', World Development, Vol. 30, No. 12, pp.2089-2107.

Pritchard, D. and McPherson, A. (2007) Strategic Destruction of the North American and European Commercial Aircraft Industry: Implication of the Systems Integration Business Model, US Trade Center, State University of New York, Buffalo, NY, Canada.

Steenhuis, H-J. and de Bruijn, E.J. (2001) 'Developing countries and the aerospace industry: match or mismatch', Technology in Society, Vol. 23, No. 4, pp.551-562.

Sweeney, P. (2008) 'Flying without succeeding? Assessing the future of the civil aircraft manufacturing sector in the People's Republic of China', The Journal of International Policy Solutions, Vol. 8, pp.3-12.

US Department of Commerce (2011) Flight Plan 2011, Analysis of the US Aerospace Industry, Office of transportation and machinery, Washington DC. 